\title{
Improve Innovation Ability of College Students through Interdisciplinary
}

\section{Education and Practice}

\author{
Haoming Lai ${ }^{1, \text { a }}$,Jianfei Lu ${ }^{2, b}$, Fei Sun ${ }^{3, C}$ \\ ${ }^{1,2,3}$ Nanchang Teachers College, Nanchang 330029,China \\ a326678218@qq.com, ${ }^{\mathrm{b}}$ 437371029@qq.com, ${ }^{\mathrm{C}}$ 13361620499@qq.com
}

\begin{abstract}
Keywords: interdisciplinary, students, innovative culture.
Abstract: Interdisciplinary has interdisciplinary, integration, creativity, complementarity and other characteristics, has an important position and role in innovative training college students, this paper analyzes the interdisciplinary dilemma nurturing creative talents among college students, and to strengthen cross-disciplinary promote Students' innovation ability of the basic idea.
\end{abstract}

Since the 20th century, interdisciplinary unprecedented speed have emerged, changing the traditional discipline structure, personnel training, especially for innovative training college students have an important role and significance. This article intends to be analyzed.

\section{First, cross-disciplinary and innovative training Students}

Cultivate innovative talents, there must be a new creative educational thought, first-class, with teaching creative ability, researchers and innovative teaching content and teaching methods, but also a first-class disciplines and academic development mechanism. Especially the development of interdisciplinary university students is an important basis for innovation education.

\section{(A) A new perspective grasps innovation College Students}

The rapid development of today's discipline, disciplinary trend has replaced differentiation trend mainstream. Interdisciplinary great practical significance in many important issues of contemporary social and technological development, interdisciplinary, integration has become an inevitable trend. Through the development of cross-boundary disciplines to promote innovative training college students, is placed in front of us has great practical significance new topic. Innovative student education requires not only excellent teachers, also need first-class disciplines. No class discipline, no rapid development of the subject, there can be no innovation College Students. Therefore, the students' culture construction and development is inseparable from the subject and cross-disciplinary integration and development of college students' innovative culture is an important indicator of success.

(B) Strengthening the discipline construction is the basis for interdisciplinary innovative training of college students

Construction is the core of the development of multi-disciplinary educational development of the students. Cross-disciplinary integration greatly broadens the horizons of scientific research; enrich the theory and methods of discipline for the development of disciplines to provide a new impetus. Therefore, the construction and development of new cross-boundary disciplines, has become the main means of achieving innovative training of college students is an important foundation for cultivating innovative talents. New cross, interdisciplinary research is the breeding ground, the cradle of culture innovative thinking and innovation, and thus is an important basis for discipline 
Students' Creative Education.

\section{Second, the plight of interdisciplinary innovation College Students faced}

\section{(A) Limit the interdisciplinary management system}

Our discipline is set by the education department of management. Disciplines must comply with national unified professional directory, and requires the approval of education authorities, so that the professional name of unity, the curriculum is similar. This system out of the market and the needs of society and can not reflect the development of new disciplines and can not be adjusted according to the development of economy and technology, unable to adapt to different levels of development and the regional characteristics of industrial development productivity, resulting in the structure and personnel training contradictions between the industrial structure, seriously affecting the interdisciplinary professional development.

\section{(B)Insufficient support Theoretical Research}

The different disciplines together to form a cross-discipline, the need for the relationship between different disciplines and interdependence have a better understanding. With respect to basic education, excessive administrative intervention and fetters university curriculum, many teaching plan is the administrative regulations, and lessons learned among colleges imitate each other's products, most of them stay In one knowing but not the why of the situation. Insufficient importance of setting an interdisciplinary professional awareness, lack of cross-disciplinary set of professional experience, interdisciplinary professional development of the internal mechanism is not sure, the lack of interdisciplinary professional theoretical guidance and appropriate skills.

(C) The concept of factors

Speak research work in a sense is a highly personal work, researchers from the stage to the entourage standing stage. In this process, local research groups and the corresponding academic leaders to emerge, they often only relates to a range of disciplines, as well as a smaller range. They tend to form in the concept of an academic shield, different disciplines are only limited to the study of this discipline, interdisciplinary between because this idea was forgotten. At the same time in order to maintain their academic status, not to learn and imitate their research to others, some of the researchers do not want to participate in interdisciplinary studies. The result is that the traditional focus on the further development of discipline, lack of communication between disciplines, even the existence of some kind of protective barriers; lack of senior personnel with interdisciplinary knowledge, and thus can not effectively guide interdisciplinary and interdisciplinary talents training; encourage interdisciplinary personnel training and interdisciplinary development policy environment is not in place.

\section{Third, interdisciplinary innovation culture in College Students}

Interdisciplinary is a feature of the 20th century, the most important scientific development is a new growth point of science, interdisciplinary plays a vital role in fostering students' innovation.

\section{(A) Interdisciplinary help cultivate innovative talents complex}

Interdisciplinary is the integration of disciplines, is the frontier of development, and reflects the discipline of rationalization, integration, market and internationalization. Training today's college students to keep up with the rapid development of the discipline, discipline adaptation of "four modernizations" We educate college students in order to develop a composite of innovative talents.

(B) Interdisciplinary help improve college students' creativity

Interdisciplinary science is often new growth point, is interdisciplinary, training students through 
interdisciplinary learning, knowledge can interact, complement each other. In solving problems to improve the professional quality, ideological quality, competency and psychological quality of college students. Students can learn from interdisciplinary medium to advanced, cutting-edge, practical knowledge, theories, methods and techniques can enhance the college students' creativity.

\section{(C) Interdisciplinary helps cultivate innovative talents}

By the organic combination of different disciplines, to build a new discipline system is to develop a multi-disciplinary background knowledge, knowledge and ability rational structure, solid critical infrastructure, the quality of comprehensive, integrated and adaptable talent. Interdisciplinary professional development not only adapted to the needs of modern scientific and technological progress and social development, but also an important factor in personnel training innovation. Interdisciplinary professional settings conducive to lay the foundation generous Students familiar subject areas adjacent to form a reasonable knowledge structure and ability to cultivate awareness and capacity from a multidisciplinary perspective and problem-solving science college students as a whole, thus contributing to improve college students ability to innovate.

\section{Fourth, strengthen the interdisciplinary Promote Students' innovation culture Basic Ideas}

\section{(A) The discipline to follow the law, breaking the "fragmentation"}

Development of the subject has its own laws, mutual penetration of different disciplines, and integrated cross has become an important trend of development of the subject, become the main way of scientific knowledge innovation. Subject fragmentation hinders cross disciplines, is not conducive to the development of the discipline. In innovative training college students, we must follow the law of development disciplines, breaking fragmented situation in order to meet the needs of development of the subject.

\section{(B)Establish academic status cross, interdisciplinary}

Interdisciplinary are generally emerging discipline, and discipline has matured compared to the interdisciplinary academic status is much lower. This requires us to pay attention to, in theory, interdisciplinary, active support interdisciplinary. Through effective mechanisms, develop a number of innovative new cross-boundary disciplines leaders, to establish a number of characteristics, there are prospects for the development of cross, interdisciplinary, innovative Students' lay a solid foundation. Through curriculum and curriculum integration, accelerate cross, interdisciplinary development. Create some cross, interdisciplinary courses to develop disciplines to penetrate course construction, inclined to cultivate talent, innovation and education in order to give the new content and ideas; offer various comprehensive programs to promote integration of various disciplines and theoretical knowledge to make disciplines and innovative Education on a new level to get more closely integrated.

(C) A reasonable, moderate, sustained incentives interaction between the various disciplines

Reasonable, moderate, sustained incentives interaction between the various disciplines can create synergy between disciplines. By absorbing the essence of the way, set the essence of the various disciplines and expertise to form a kind of innovation, to build a new disciplinary system by the new disciplinary system, promote the Students' Innovation System, now we want to create a series based on the emerging interdisciplinary field concepts, relationships, methods, and evaluation criteria, thus forming a new internal logic of knowledge.

(D) A combination of research development of interdisciplinary

Student's innovative training to achieve the final analysis from the research practice. It is also inseparable from the development of cross-disciplinary research practice. A combination of research for the development between the two to provide a broad space for development. From the practice 
of research, not only can cultivate the creativity to adapt to social and economic development, the most important thing is to promote reasonable professional structure, promote the development of cross-disciplinary. Not just high-tech enterprise involved in a discipline, it is the product of cross-development of multi-disciplinary, through a combination of research, in favor of continuing to promote the development of the discipline, promoting knowledge and innovation, promote innovation College Students.

In short, the emphasis on interdisciplinary, based on support for strengthening the Interdisciplinary Innovation is an important task of Creative Education of College Students Work. A positive attitude and effective measures, multidisciplinary cross, combined, will greatly facilitate our students carry out scientific research, innovative training guide and encourage students to field update, the higher goal lever forward, resulting in more the major innovation research has independent intellectual property rights, thus greatly improving the quality of college students' innovative culture.

\section{References}

[1] $\mathrm{Hu}$ Haiyan establishes mechanisms to promote innovation in emerging disciplines, cross, interdisciplinary construction [J]. Degrees and Graduate Education, 2003 (2)

[2] Ying, Dong Junguo, high into the clouds. Interdisciplinary is the cradle of cultivating outstanding graduate students [J]. Degrees and Graduate 2001 (2)

[3] Wangen Hua University disciplines - Cross-disciplinary fusion [J] Hunan First Normal College, $2003(3)$ 